\title{
Synthesis and Functions of Polystyrene Derivatives Having Pendant Oligosaccharides
}

\author{
Kazukiyo KobaYashi, Hiroshi Sumitomo, and Yoshimitsu INA \\ Faculty of Agriculture, Nagoya University, \\ Chikusa, Nagoya 464, Japan
}

(Received July 24, 1984)

\begin{abstract}
Polystyrene derivatives with maltose, lactose, and maltotriose substituents on each benzene ring were prepared by coupling the corresponding oligosaccharide lactones with $p$ vinylbenzylamine, followed by radical polymerization. The polymers were water-soluble and had tightly-coiled conformations in water. Strong interactions with methyl orange and magnesium 1anilino-8-naphthalenesulfonate were observed and their binding constants were determined and compared. Maltose and maltotriose-containing polymers interacted with concanavalin A specifically.
\end{abstract}

KEY WORDS Radical Polymerization / Oligosaccharide-Containing Polymers / Water-Soluble Polymers / Binding of Organic Solutes / Concanavalin A / Lectins /

Oligosaccharide chains of glycolipids and glycoproteins protrude from the surface of cell membranes and function as recognition markers for hormones, enzymes, lectins, and proteins. ${ }^{1.2}$ Synthetic polymers endowed with oligosaccharides as informational elements are of interest in connection with pharmacological and biomedical applications. ${ }^{3}$ There have been several reports ${ }^{4-10}$ on solid-phase supports to which oligosaccharides are linked. The polymer-bound oligosaccharides have been used as intermediates in the synthesis of oligosaccharides $^{4-6}$ and supports for affinity chromatography. ${ }^{7-10}$ However, little has been reported on linear and soluble polymers containing pendant oligosaccharides ${ }^{11-13}$ and cyclodextrins. ${ }^{14.15}$

The present investigation has aimed at developing a simple synthetic method to prepare polymers having not only pendant oligosaccharides but also pendant polysaccharides. A previous paper of this series was concerned with the water-soluble homopolymer 1 obtained by the polymerization of $N$ - $p$-vinylben-
zyl-D-gluconamide. ${ }^{16}$ In the present paper, the oligosaccharide-containing polymers 2,3 , and 4 are prepared from maltose $(O-\alpha$-D-glucopyranosyl-( $1 \rightarrow 4)$-D-glucopyranose), lactose $(O-\beta$-D-galactopyranosyl- $(1 \rightarrow 4)$-D-glucopyranose), and maltotriose $(O-\alpha$-D-glucopyranosyl)-( $1 \rightarrow 4)-O$ - $\alpha$-D-glucopyranosyl-( $1 \rightarrow$ 4)-D-glucopyranose) as the respective starting materials. In each repeating unit of these polymers, the reducing end of the oligosaccharide is in amide linkage with the main chain $p$ vinylbenzylamine. The synthetic route is shown in Scheme I, using as an example polymer 2. It includes oxidation of maltose, coupling of the resulting lactone with $p$-vinylbenzylamine, and subsequent radical homopolymerization.

Each structural unit of the polymers is an amphiphile consisting of hydrophilic carbohydrate and hydrophobic vinylbenzyl moieties. It was already reported ${ }^{16-18}$ that monosaccharide-containing polystyrenes has a strong affinity for organic solutes in water. The binding ability was assumed to be attributable to 


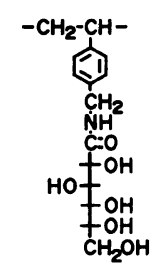

1
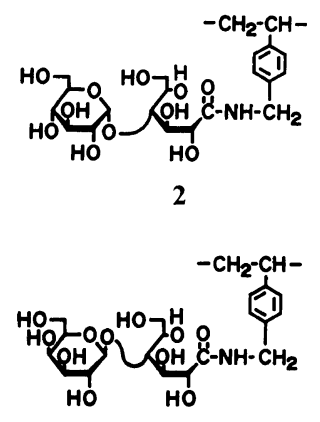

3
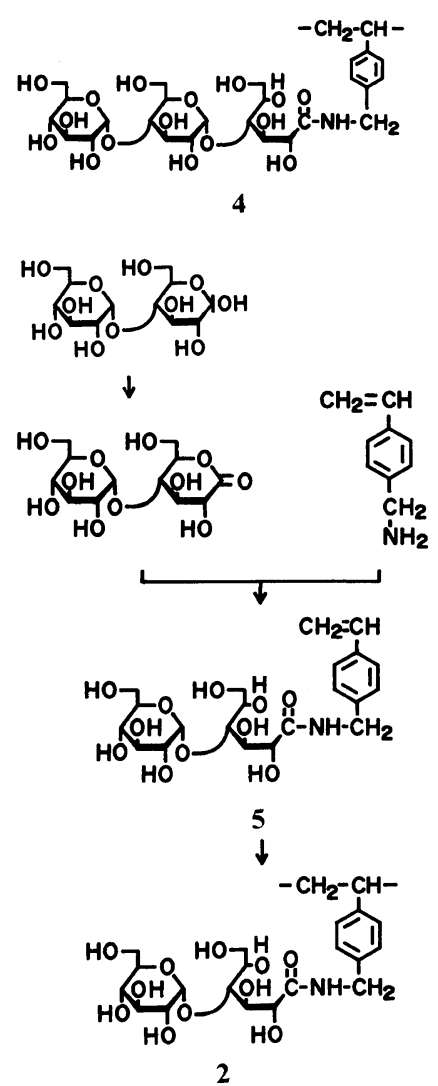

Scheme I. Synthesis and polymerization of $N$-pvinylbenzyl-[O- $\alpha$-D-glucopyranosyl-( $1 \rightarrow 4)]-\mathrm{D}-$ gluconamide (5). the tightly-coiled conformation induced by their amphiphilic structures. In this paper, the binding of methyl orange and magnesium 1anilino-8-naphthalenesulfonate (ANS) to the polystyrene derivatives with di- and trisaccharide substituents is investigated.

As part of a study on the biological functions of oligosaccharide-containing polymers, we focused our attention on the interaction with a lectin, concanavalin A (Con A). Lectins are highly specific carbohydrate-binding proteins that agglutinate cells and/or precipitate glycoconjugates. ${ }^{19,20}$ Con $\mathrm{A}$, isolated from jack bean, is a tetramer with 4 carbohydrate binding sites. ${ }^{21,22}$ It specifically binds to $\alpha$-Dmannopyranosyl or $\alpha$-D-glucopyranosyl residues at the nonreducing termini of oligo- and polysaccharides. We show that some of the present polymers interacted specifically with Con A.

\section{EXPERIMENTAL}

\section{p-Vinylbenzylamine}

This compound was prepared from $p$ vinylbenzyl chloride ${ }^{23}$ according to the Gabriel synthesis. ${ }^{16}$

\section{Oxidation of Oligosaccharides ${ }^{24}$}

Maltose-1-hydrate $(12 \mathrm{~g}, 33 \mathrm{mmol})$ was dissolved in water $(9 \mathrm{ml})$, diluted with methanol $(25 \mathrm{ml})$, and added to an iodine $(17.1 \mathrm{~g})$ solution in methanol $(240 \mathrm{ml})$ at $40^{\circ} \mathrm{C}$. At this temperature, a $4 \%$ potassium hydroxide solution in methanol $(400 \mathrm{ml})$ was added dropwise with magnetic stirring for $35 \mathrm{~min}$ until the color of iodine disappeared. The solution was cooled externally in an ice-bath. The precipitated crystalline product was filtered, washed with cold methanol, and then cold ether, and recrystallized from a mixture $(800 \mathrm{ml})$ of methanol and water $(9: 1, \mathrm{v} / \mathrm{v})$. Yield was $10.7 \mathrm{~g}(81 \%)$.

The resulting potassium maltonate was then converted to the free acid by passing the aqueous solution through a column of 
Amberlite IR-120B $\left(\mathrm{H}^{+}\right)$. The acidic eluate was collected and concentrated in a rotary evaporator. Repeated evaporation of methanol and ethanol solution converted the maltonoic acid into maltonolactone containing a small amount of water in a quantitative yield.

Lactose and maltotriose were oxidized in the same way.

$N$-p-Vinylbenzyl-[O- $\alpha$-D-glucopyranosyl- $(1 \rightarrow$ 4) ]-D-gluconamide (5)

Maltonolactone $(9.2 \mathrm{~g}, 27 \mathrm{mmol})$ was dissolved in refluxing methanol $(90 \mathrm{ml})$ and a $p$ vinylbenzylamine $(3.7 \mathrm{~g}, 27 \mathrm{mmol})$ solution in methanol $(20 \mathrm{ml})$ was added. The mixed solution was refluxed with magnetic stirring for $120 \mathrm{~min}$ and allowed to stand at room temperature to yield a white crystal. The crystal was filtered, washed with a small amount of cold methanol, and dried in vacuo $(10.5 \mathrm{~g}$, $82 \%$ ). It was purified by recrystallization from methanol. mp $197-197.5^{\circ} \mathrm{C} ;[\alpha]_{\mathrm{D}}^{25}+91.3^{\circ}$ $\left(c=1\right.$ in $\left.\mathrm{Me}_{2} \mathrm{SO}\right)$. Anal. Calcd for $\mathrm{C}_{21} \mathrm{H}_{31}$ $\mathrm{NO}_{11}$ : C, $53.27 \%$; H, 6.60\%; N, $2.96 \%$. Found: $\mathrm{C}, 53.26 \%$; H, 6.61\%; N, 2.83\%. ${ }^{13} \mathrm{C}$ NMR (25 MHz, $\mathrm{Me}_{2} \mathrm{SO}-d_{6}$, TMS. Primes designate the terminal $\alpha$-D-glucopyranosyl residue) $\delta 172.2 \mathrm{C}=\mathrm{O}, 139.2$ and 135.4 phenyl (ipso), 136.3 $-\mathrm{CH}=\mathrm{CH}_{2}, 127.2$ and 125.7 phenyl (meta and ortho), $113.5=\mathrm{CH}_{2}, 100.6 \mathrm{C}\left(1^{\prime}\right)$, $82.9 \mathrm{C}(4), 69.8 \mathrm{C}\left(4^{\prime}\right), 62.5 \mathrm{C}(6), 60.5 \mathrm{C}\left(6^{\prime}\right)$, 41.5 benzyl methylene, $73.1,72.0$, and 71.6 ppm the remaining pyranose carbons.

\section{$N$-p-Vinylbenzyl-[O- $\beta$-D-galactopyranosyl-}

\section{( $1 \rightarrow 4$ ) ]-D-gluconamide (6)}

The preparative method was similar to that of 5. Yield, $87 \%$; mp $183-184^{\circ} \mathrm{C} ;[\alpha]_{\mathrm{D}}^{25}+29.1^{\circ}$ ( $c=1$ in $\left.\mathrm{Me}_{2} \mathrm{SO}\right)$. Anal. Calcd for $\mathrm{C}_{21} \mathrm{H}_{31}$ $\mathrm{NO}_{11}$ : C, $53.27 \%$; H, 6.60\%; N, 2.96\%. Found: $\mathrm{C}, 53.24 \%$; H, 6.62\%; N, 3.10\% ${ }^{13} \mathrm{C}$ NMR $\left(50 \mathrm{MHz}, \mathrm{Me}_{2} \mathrm{SO}-d_{6}\right.$, TMS. Primes designate the terminal $\beta$-D-galactopyranosyl residue) $\delta 172.0 \mathrm{C}=\mathrm{O}, 138.9$ and 135.2 phenyl (ipso), $136.1-\underline{\mathrm{CH}}=\mathrm{CH}_{2}, 127.0$ and 125.6 phenyl
( meta and ortho), $113.3=\mathrm{CH}_{2}, 104.3 \mathrm{C}\left(1^{\prime}\right)$, $82.7 \mathrm{C}(4), 68.0 \mathrm{C}\left(4^{\prime}\right), 62.2 \mathrm{C}(6), 60.5 \mathrm{C}\left(6^{\prime}\right)$, 41.5 benzyl methylene, 75.5, 73.1, 71.9, 71.3, 70.9 and $70.5 \mathrm{ppm}$ the remaining pyranose carbons.

$N$-p-Vinylbenzyl-[O- $\alpha$-D-glucopyranosyl$(1 \rightarrow 4)$-O- $\alpha$-D-glucopyranosyl- $(1 \rightarrow 4)]$-Dgluconamide (7)

It was prepared similarly as 5 . Yield, $66 \%$; mp $114-116^{\circ} \mathrm{C} ;[\alpha]_{\mathrm{D}}^{25}+116^{\circ}\left(c=1\right.$ in $\left.\mathrm{Me}_{2} \mathrm{SO}\right)$. Anal. Calcd for $\mathrm{C}_{27} \mathrm{H}_{41} \mathrm{NO}_{16}: \mathrm{C}, 51.02 \% ; \mathrm{H}$, $6.50 \%$; N, $2.20 \%$. Found: C, $49.98 \% ; \mathrm{H}$, $6.63 \% ; \quad \mathrm{N}, \quad 2.26 \% .{ }^{13} \mathrm{C} \quad \mathrm{NMR} \quad(25 \mathrm{MHz}$, $\mathrm{Me}_{2} \mathrm{SO}-d_{6}$, TMS. Primes and double primes designate the central and terminal $\alpha$-D-glucopyranosyl residues, respectively) $\delta 172.1 \mathrm{C}=$ $\mathrm{O}, 139.1$ and 135.3 phenyl (ipso), 136.2 $\underline{\mathrm{CH}}=\mathrm{CH}_{2}, 127.1$ and 125.7 phenyl (meta and ortho), $113.5=\mathrm{CH}_{2}, 100.6$ and $100.2 \mathrm{C}\left(1^{\prime}\right)$ and $\mathrm{C}\left(1^{\prime \prime}\right), 82.7 \mathrm{C}(4), 79.4 \mathrm{C}\left(4^{\prime}\right), 69.8 \mathrm{C}\left(4^{\prime \prime}\right), 62.4$ $\mathrm{C}(6), 60.7$ and $59.9 \mathrm{C}\left(6^{\prime}\right)$ and $\mathrm{C}\left(6^{\prime \prime}\right), 41.4$ benzyl methylene, $73.1,72.1$, and $71.4 \mathrm{ppm}$ the remaining pyranose carbons.

\section{Polymerization}

Monomer, initiator, and solvent were charged in a glass ampule, frozen in a solid carbon dioxide-methanol bath, and degassed three times. The ampule was sealed under reduced pressure and maintained in a thermostat at $60 \pm 0.05^{\circ} \mathrm{C}$. The solution was chilled and poured into cold methanol. The product was reprecipitated from its aqueous solution into methanol five times and freeze-dried from an aqueous solution.

Anal. 2, Calcd for $\left(\mathrm{C}_{21} \mathrm{H}_{31} \mathrm{NO}_{11}\right)_{n}$ : C, $53.27 \%$; H, $6.60 \%$; N, 2.96\%. Found: C, $53.26 \% ; \mathrm{H}, 6.60 \% ; \mathrm{N}, 2.89 \%$. 3, Calcd for $\left(\mathrm{C}_{21} \mathrm{H}_{31} \mathrm{NO}_{11}\right)_{n}$ : C, $53.27 \% ; \mathrm{H}, 6.60 \% ; \mathrm{N}$, $2.96 \%$. Found: C, $53.32 \% ; \mathrm{H}, 6.62 \% ; \mathrm{N}$, $2.95 \%$. 4, Calcd for $\left(\mathrm{C}_{27} \mathrm{H}_{41} \mathrm{NO}_{16}\right)_{n}$ : C, $51.02 \% ; \mathrm{H}, 6.50 \%$; N, $2.20 \%$. Found: C, $51.01 \%$; H, 6.47\%; N, $2.09 \%$. 


\section{Characterization}

NMR spectra were recorded on JEOL JNM-FX-100 and JNM-FX-200 Fourier transform NMR spectrometers, dimethyl sulfoxide- $d_{6}\left(\mathrm{Me}_{2} \mathrm{SO}-d_{6}\right)$ and tetramethylsilane being used as the solvent and internal standard. IR spectra were measured as $\mathrm{KBr}$ disks with a JASCO IR-3 infrared spectrophotometer. Optical rotations were determined with a JASCO DIP-181 digital polarimeter using a 1-dm cell. Viscosities were measured in Ubbelohde viscometers at $25^{\circ} \mathrm{C}$.

\section{Binding of Oraganic Solutes}

Binding of methyl orange and ANS was measured at room temperature with a JASCO UVIDEC 505 digital double-beam spectrophotometer and JASCO FP-550 spectrofluorometer. Methyl orange was of reagent grade and ANS was recrystallized twice from hot water. Phosphate buffer at $\mathrm{pH} 6.88$ was used as the solvent. The polymer concentration $[\mathrm{P}]$ expressed on the basis of a repeating structural unit was varied between $10^{-3}$ and $7 \times 10^{-3} \mathrm{M}$, while the methyl orange concentration was kept constant at $1 \times 10^{-4}$ and $5 \times$ $10^{-4} \mathrm{M}$ and the ANS concentration at $1 \times$ $10^{-5}, 2 \times 10^{-5}$, and $5 \times 10^{-5} \mathrm{M}$.
Interaction between Con $A$ and the Polymers $^{25.26}$

Con A was purchased from the Sigma Chemical Co. Buffer solutions $(0.01 \mathrm{M}$ phosphate, $\mathrm{pH} 7.2 ; 0.5 \mathrm{M} \mathrm{NaCl} ; 0.1 \mathrm{mM} \mathrm{MnCl}_{2}$; and $0.1 \mathrm{mM} \mathrm{CaCl}_{2}$ ) of Con $\mathrm{A}$ and the polymer were mixed and shaken at room temperature. At regular intervals, turbidity of the mixture was measured at $360 \mathrm{~nm}$ with a JASCO UVIDEC 505 digital double-beam spectrophotometer.

\section{RESULTS AND DISCUSSION}

\section{Synthesis}

According to Scheme I, the reducing ends of maltose, lactose, and maltotriose were oxidized by hypoiodite, and then the resulting lactones were condensed with $p$-vinylbenzylamine in refluxing methanol. This simple method has several advantages: each yield is high and the oligosaccharides need no protection of the hydroxyl groups. We may expect this procedure to be applicable to polysaccharides having reducing ends. The crystalline compounds obtained had sharp melting points and were soluble in water, dimethyl sulfoxide $\left(\mathrm{Me}_{2} \mathrm{SO}\right)$, dimethylformamide, pyridine, and

Table I. Polymerization ${ }^{a}$

\begin{tabular}{|c|c|c|c|c|c|c|c|c|c|c|c|c|}
\hline \multirow{2}{*}{$\begin{array}{l}\text { Exp. } \\
\text { No. }\end{array}$} & \multicolumn{2}{|c|}{ Monomer ${ }^{\mathrm{b}}$} & \multicolumn{2}{|c|}{ Initiator } & \multicolumn{2}{|c|}{ Solvent } & \multirow{2}{*}{$\frac{\text { Time }}{\mathrm{h}}$} & \multicolumn{2}{|c|}{ Polymer yield } & \multirow{2}{*}{$\frac{[\alpha]_{\mathrm{D}}^{25 \mathrm{c}}}{\operatorname{deg}}$} & \multicolumn{2}{|c|}{$[\eta]^{\mathrm{d}}$} \\
\hline & & $\mathrm{g}$ & & $\mathrm{mol}^{\%} \%$ & & $\mathrm{ml}$ & & & $\%$ & & In $\mathrm{Me}_{2} \mathrm{SO}$ & In $\mathrm{H}_{2} \mathrm{O}$ \\
\hline 24 & 5 & 2.37 & AIBN & 0.5 & $\mathrm{Me}_{2} \mathrm{SO}$ & 5 & 9 & 2 & 31 & +102 & 0.52 & 0.15 \\
\hline 25 & 5 & 2.37 & AIBN & 0.3 & $\mathrm{Me}_{2} \mathrm{SO}$ & 5 & 14 & 2 & 93 & +100 & 1.09 & 0.26 \\
\hline 26 & 5 & 2.37 & AIBN & 0.2 & $\mathrm{Me}_{2} \mathrm{SO}$ & 4 & 14 & 2 & 93 & +100 & 1.35 & 0.30 \\
\hline 30 & 5 & 0.95 & $\mathrm{~K}_{2} \mathrm{~S}_{2} \mathrm{O}_{8}$ & 0.2 & $\mathrm{H}_{2} \mathrm{O}$ & 2 & 11 & 2 & 90 & +99.2 & 1.10 & 0.26 \\
\hline 27 & 6 & 2.37 & AIBN & 0.5 & $\mathrm{Me}_{2} \mathrm{SO}$ & 5 & 11 & 3 & 87 & +36.1 & 0.60 & 0.22 \\
\hline 31 & 6 & 2.37 & AIBN & 0.3 & $\mathrm{Me}_{2} \mathrm{SO}$ & 5 & 14 & 3 & 96 & +35.1 & 0.92 & 0.32 \\
\hline 32 & 6 & 2.37 & AIBN & 0.2 & $\mathrm{Me}_{2} \mathrm{SO}$ & 4 & 14 & 3 & 95 & +34.7 & 1.20 & 0.41 \\
\hline 36 & 6 & 0.95 & $\mathrm{~K}_{2} \mathrm{~S}_{2} \mathrm{O}_{8}$ & 0.2 & $\mathrm{H}_{2} \mathrm{O}$ & 2 & 14 & 3 & 98 & +36.0 & 1.09 & 0.46 \\
\hline 34 & 7 & 1.27 & AIBN & 0.5 & $\mathrm{Me}_{2} \mathrm{SO}$ & 2 & 14 & 4 & 86 & +130 & 1.50 & 0.44 \\
\hline 35 & 7 & 1.27 & $\mathrm{~K}_{2} \mathrm{~S}_{2} \mathrm{O}_{8}$ & 0.2 & $\mathrm{H}_{2} \mathrm{O}$ & 2 & 14 & 4 & 89 & +131 & 1.38 & 0.68 \\
\hline
\end{tabular}

a Temp., $60^{\circ} \mathrm{C}$.

b The systematic names of the monomers are given in the experimental section.

c $1 \mathrm{~g} / 100 \mathrm{ml}$ in $\mathrm{Me}_{2} \mathrm{SO}$.

d At $25^{\circ} \mathrm{C}$. Calculation was made using the concentration expressed in $\mathrm{g} / 100 \mathrm{ml}$. 

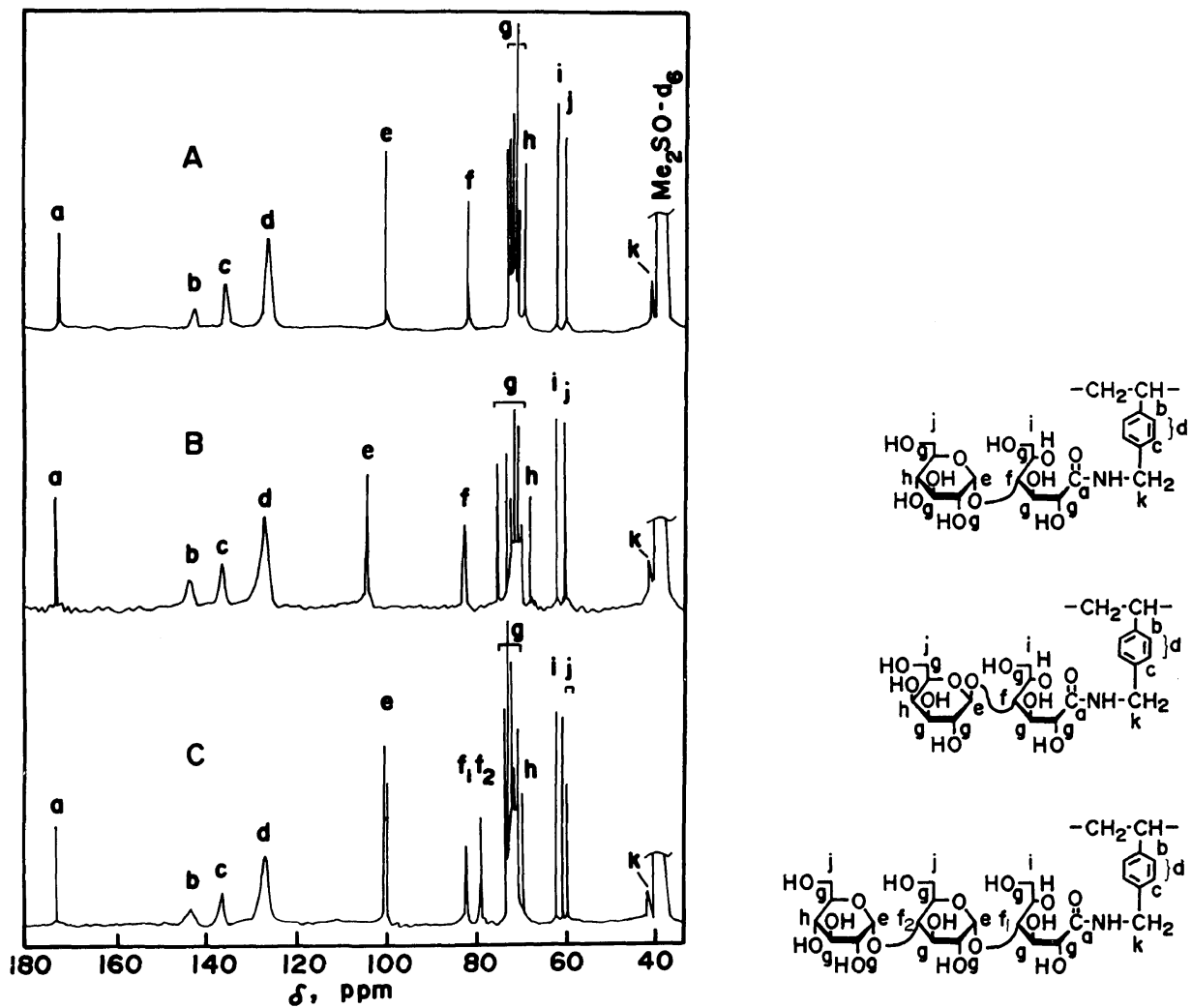

Figure 1. ${ }^{13} \mathrm{C}$ NMR spectra of the polymers. Solvent, $\mathrm{Me}_{2} \mathrm{SO}-d_{6} ; 5 \mathrm{~mm} \phi$ tube; $\mathrm{Me}_{4} \mathrm{Si}$ standard; $50 \mathrm{MHz}$. A, $2 ; 7 \% ; 80^{\circ} \mathrm{C} ; 28400$ scans. B, 3; $7 \% ; 45^{\circ} \mathrm{C} ; 10000$ scans. C, $4: 9 \% ; 70^{\circ} \mathrm{C} ; 20000$ scans.

hot methanol. The formation of the amide linkage was confirmed by infrared absorptions at $1640\left(v_{\mathrm{C}=\mathrm{O}}\right)$ and $1550 \mathrm{~cm}^{-1}\left(\delta_{\mathrm{N}-\mathrm{H}}\right)(\mathrm{KBr}$ disks). There also appared a triplet of the $\mathrm{N}-\mathrm{H}$ proton resonance at $8.1 \mathrm{ppm}$ and a $\mathrm{C}=\mathrm{O}{ }^{13} \mathrm{C}$ resonance at $172 \mathrm{ppm}$.

The polymerization was carried out with azobisisobutyronitrile (AIBN) as the initiator in $\mathrm{Me}_{2} \mathrm{SO}$ and with potassium peroxydisulfate $\left(\mathrm{K}_{2} \mathrm{~S}_{2} \mathrm{O}_{8}\right)$ in water at $60^{\circ} \mathrm{C}$ as summarized in Table I. The polymerization proceeded homogeneously, and white powdery polymers were isolated by freeze-drying from aqueous solutions. They were soluble in water and $\mathrm{Me}_{2} \mathrm{SO} ; 2$ was also soluble in pyridine. The elementary analyses of the polymers corresponded to those expected (see Experimental section).
The ${ }^{13} \mathrm{C}$ NMR spectra depicted in Figure 1 reveal some structural features of these polymers. The peak a at $172 \mathrm{ppm}$ was the carbonyl carbon resonance. The anomeric $\mathrm{C}-1$ signal appeared as peak e: $\alpha$-D-glucopyranosyl C-1 of 2 at $100.5 \mathrm{ppm}$ and $\beta$-D-galactopyranosyl C-1 of 3 at $104.3 \mathrm{ppm}$. The polymer 4 had two $\alpha$-Dglucopyranosyl C-1 resonances at 100.5 and $100.2 \mathrm{ppm}$, which came from the central and terminal residues, respectively. The C- 4 resonance of the nonterminal residue appeared as peak $\mathrm{f}$. The peaks at 82.7 (2), 82.8 (3), and $82.5 \mathrm{ppm}(4)$ are due to the D-gluconamide C-4 and that at $79.5 \mathrm{ppm}$ (4) to the central $\alpha$-Dglucopyranosyl C-4. The peak $h$ of 2 (70.2) and $4(70.2 \mathrm{ppm})$ was attributable to the terminal $\alpha$-D-glucopyranose C-4, and distinguishable from the $\beta$-D-galactopyranose C-4 of 3 (68.1 
ppm). The peak i (62.6 for $2,62.2$ for 3 , and $62.5 \mathrm{ppm}$ for 4) and j (61.0 for 2, 60.5 for 3 , 61.0 and $60.4 \mathrm{ppm}$ for 4) were the C-6 hydroxymethyl resonances. Being $1.6-2.1 \mathrm{ppm}$ downfield, the peak i was assignable to the Dgluconamide C-6. Several peaks designated as $\mathrm{g}$ were also well-resolved, but further assignment of the remaining pyranose carbons was not attempted. These carbohydrate resonances were similar to those of the corresponding monomers (see Experimental section).

In contrast to the sharp signals of the carbohydrate moieties described above, the phenyl carbon signals b (143), c (136), and d (127 ppm) were broad. When $\mathrm{D}_{2} \mathrm{O}$ was used as the solvent, the broadening of the main chain methylene and methine ( $\sim 43 \mathrm{ppm})$ became apparent in addition to the more broadening of the phenyl signals. Stacking of the phenyl groups and small mobility of the main chain were suggested.

As shown in Table I, the intrinsic viscosities of the polymers increased with decreasing amount of AIBN. Some of the intrinsic viscosities determined in $\mathrm{Me}_{2} \mathrm{SO}$ were higher than 1.0 , suggesting these polymers to be of high molecular weight. However, the intrinsic viscosities determined in water were only about $20-40 \%$ of those in $\mathrm{Me}_{2} \mathrm{SO}$. We assumed that the low viscosities reflected tightly-coiled conformations of these polymers in water. The micellar characteristics of the polymers led us to study the binding of organic solutes.

\section{Binding of Methyl Orange and ANS}

Polymers 2, 3, and $\mathbf{4}$ when dissolved in water interacted with the organic solutes. The addition of the polymers to an aqueous solution of methyl orange decreased the optical density of the dye. The difference in optical density was recorded between a reference solution of methyl orange and sample solutions containing the same concentration of methyl orange and various concentrations of the polymers. In the difference absorption spectra, there appeared two minima at 390 and $490 \mathrm{~nm}$ and an isosbestic point at $340 \mathrm{~nm}$. The presence of an isosbestic point indicated that there exist free and bound methyl orange species. The concentrations of these species $\left([\mathrm{MO}]_{\mathrm{F}}\right.$ and $\left.[\mathrm{MO}]_{\mathrm{B}}\right)$ were estimated according to a method using the Benesi-Hildebrand relationship. ${ }^{17.27}$ The wavelength $\left(\lambda_{\mathrm{B}, \max }\right)$ and molar absorbance $\left(\varepsilon_{\mathrm{B}, \max }\right)$ of the absorption maximum of the bound methyl orange species were also obtained.

The Klotz relationship (eq 1) ${ }^{17.28}$ employing $[\mathrm{MO}]_{\mathrm{F}}$ and $[\mathrm{MO}]_{\mathrm{B}}$ was plotted in Figure 2. From the slopes of the straight lines were calculated the respective binding constants

$$
\frac{[\mathrm{P}]}{[\mathrm{MO}]_{\mathrm{B}}}=\frac{1}{[\mathrm{MO}]_{\mathrm{F}}} \cdot \frac{1}{K n}+\frac{1}{n}
$$

$(K n)$, which agreed with the Benesi-Hildebrand binding constants $\left(K^{\prime}\right)$. Table II summarizes these binding characteristics including $K^{*}$. $K^{*}$ refers to the binding constant expressed in $10^{5} \mathrm{~g}$ of polymer, a unit frequently used in the literature to compare binding capacities of various polymers. ${ }^{29-32}$ These constants were independent of the molecular weight of the polymers used. The term $1 / n$ in eq 1 represents the minimum number of monomer units required to bind a solute molecule. However, there was some uncertainty in the determination of the intercept of Figure 2 and hence the matter is not discussed.

The interaction of the polymers with ANS was investigated by spectrofluorometry. The fluorescence of ANS in aqueous solution was strongly enhanced by addition of the polymers. The binding characteristics in Table II were obtained in a similar way.

The wavelength of absorption and fluorescence maxima of the organic solutes may be a measure of the polarity in the immediate vicinity of the species. The polymers 1-4 induced a blue-shift of the main $464 \mathrm{~nm}$ methyl orange absorption by $15-20 \mathrm{~nm}$ and also of $525 \mathrm{~nm}$ ANS fluorescence by $45 \mathrm{~nm}$. This shift suggests that both solutes were bound to a hydrophobic region of the polymers. 
The binding constants listed demonstrate the strong affinity of these polymers for the organic solutes. The methyl orange binding constants were higher than or comparable to those reported for poly(vinyl pyrrolidone) $\left(K^{*}=2.7 \times 10^{4}\right),{ }^{29}$ a monosaccharide-containing polymer $\left(K^{*}=3.0 \times 10^{4}\right),{ }^{17}$ and bovine serum albumin $\left(K^{*}=6.1 \times 10^{4}\right) .{ }^{29}$ The $K^{*}$ 's of $\beta$-cyclodextrin ${ }^{30}$ and a monosaccharide-containing polymer ${ }^{18}$ for ANS were $0.49 \times 10^{4}$ and

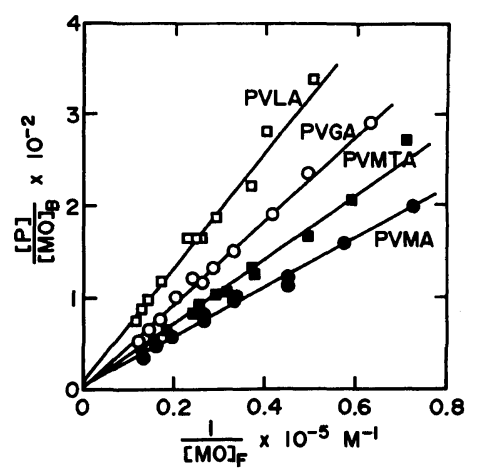

Figure 2. Klotz relationship for binding of methyl orange to polymers at room temperature. PVGA, 1; PVMA, 2; PVLA, 3; PVMTA, 4.
$4.1 \times 10^{4}$, respectively. On the other hand, polystyrene derivatives with crown ether or linear oligomeric oxyethylene $\left(\mathrm{O}\left(\mathrm{CH}_{2} \mathrm{CH}_{2} \mathrm{O}\right)_{n}\right.$ $\mathrm{CH}_{3}$ ) substituents on the benzenes ring were reported to possess much stronger capacity for methyl orange $\left(K^{*}=33.4 \times 10^{4}\right.$ and $70 \times 10^{4}$, respectively). ${ }^{31.32}$

Polymers 1-4 are nonionic macromolecules which carry no specific binding sites such as charged groups, long alkyl chains, inclusion cavities, and cross linking. As described earlier, the strong affinity of the polymers for organic solutes was assumed to be attributable to the polymer conformation induced by the amphiphilic structure. The vinylbenzyl residues aggregated to form hydrophobic regions surrounded by hydrated carbohydrate residues. Organic solutes were held strongly in the hydrophobic regions in a micelle-like conformation.

Of the four polymers listed in Table II, 2 having the side chain of the maltose derivative was most effective in binding both solutes. This strong binding ability may be ascribed to

Table II. Binding of methyl orange (MO) and magnesium 1-anilino8-naphthalenesulfonate (ANS) to the polymers

\begin{tabular}{|c|c|c|c|c|c|c|}
\hline \multirow{2}{*}{ Solute } & \multirow{2}{*}{ Polymer } & $\lambda_{\mathrm{B}, \max }{ }^{\mathrm{a}}$ or $\lambda_{\mathrm{B}, \max }^{\mathbf{F}}$ & \multirow{2}{*}{$\varepsilon_{\mathrm{B}, \max }{ }^{\mathrm{c}}$ or $I_{\infty} / I_{0}^{\mathrm{d}}$} & \multirow{2}{*}{$\frac{K^{\prime \mathrm{e}}}{\mathrm{M}^{-1}}$} & \multirow{2}{*}{$\frac{K n^{\mathrm{f}}}{\mathbf{M}^{-1}}$} & \multirow{2}{*}{$\frac{K^{*} \times 10^{-4 \mathrm{~g}}}{\left(10^{5} \mathrm{gl}^{-1}\right)^{-1}}$} \\
\hline & & $\mathrm{nm}$ & & & & \\
\hline MO & $1^{\mathrm{h}}$ & $450^{\mathrm{a}}$ & $21000^{c}$ & 220 & 220 & 7.1 \\
\hline MO & 2 & $450^{\mathrm{a}}$ & $21500^{\mathrm{c}}$ & 350 & 370 & 7.8 \\
\hline MO & 3 & $455^{\mathrm{a}}$ & $22300^{c}$ & 150 & 160 & 3.4 \\
\hline MO & 4 & $455^{a}$ & $23200^{c}$ & 280 & 290 & 4.6 \\
\hline ANS & $1^{\mathrm{i}}$ & $477^{\mathrm{b}}$ & $360^{d}$ & 120 & 110 & 3.5 \\
\hline ANS & 2 & $480^{b}$ & $290^{d}$ & 260 & 290 & 6.1 \\
\hline ANS & 3 & $480^{b}$ & $280^{\mathrm{d}}$ & 180 & 190 & 4.0 \\
\hline ANS & 4 & $480^{\mathrm{b}}$ & $290^{d}$ & 250 & 290 & 4.6 \\
\hline
\end{tabular}

${ }^{a}$ Wavelength of the absorption maximum of the bound methyl orange.

b Wavelength of the fluorescence maximum of the bound ANS.

c Molar absorbance of the bound methyl orange.

${ }^{d}$ Relative fluorescence intensity of the bound ANS.

e Binding constant of the Benesi-Hildebrande relationship based on a structural unit.

f Binding constant of the Klotz relationship based on a structural unit.

g Binding constant, based on a unit weight $\left(10^{5} \mathrm{~g}\right)$ of polymer, was derived from $\mathrm{Kn}$.

h Data from ref 17.

i Data from ref 18. 
a moderate hydrophilic-lipophilic balance regulated primarily by the length of the oligosaccharide moiety. However, another disaccharide-containing polymer 3 was also inferior to 2 , indicating that structural factors other than the length should be considered. Several reports ${ }^{33.34}$ suggest that not only is an oligosaccharide hydrophilic in character but its certain surface is hydophobic; this character depends on both configuration and conformation of the oligosaccharide. It is probable that the hydrophobic character of oligosaccharides affects the micellar structures and some subtle differences in the micellar structure change the binding ability and also viscosity behavior in water. However, we have not yet reached reasonable estimates of factors which explain the binding strength of polymers and orders in binding constants for methyl orange $(2>1>4>3)$ and ANS $(2>4>3>1)$.

\section{Interaction between Con $A$ and the Polymers}

When polymers 2 and $\mathbf{4}$ were mixed with Con $\mathrm{A}$ in a buffer solution, the turbidity of the solution increased and soon a precipitate was deposited. The precipitate, however, dissolved by the addition of a monosaccharide D-mannose, and a clear solution was restored. Precipitation can be rationalized on the basis of cross linkage between the tetrameric Con A molecule and multivalent polymer molecule carrying glucose residues in each repeating unit. When D-mannose was added, the more sensitive monovalent receptor expelled the glucose residues from the binding sites resulting in dissociation of the multivalent interaction.

Polymer $\mathbf{4}$ caused precipitation faster than 2 . The precipitate of $\mathbf{4}$ appeared after 1 h's mixing under the conditions employed, and that of $\mathbf{2}$ did so after $4 \mathrm{~h}$ 's. It seems likely that the terminal glucose residue of the trisaccharide chain was more accessible to the binding site in a deep cavity of Con A than that of the disaccharide chain was. ${ }^{35}$ On the other hand, the action of D-mannose was rapid, requiring less than $30 \mathrm{~min}$ for complete dissolution of the precipitate.

Polymer 3 did not precipitate Con A although only a slight and slow increase in turbidity was observed. There was probably no appreciable interaction between 3 and Con A since the latter carries no binding site for galactose. Polymer 1 caused no precipitation, but a considerable increase in turbidity was observed which did not decrease with the addition of D-mannose. Some nonspecific, probably hydrophobic force might be involved between Con $\mathrm{A}$ and 1. ${ }^{19}$

Thus the oligosaccharide chains of the polymers could be distinguished by Con A.

\section{REFERENCES}

1. N. Sharon, "Complex Carbohydrates, Their Chemistry, Biochemistry, and Functions," Addison Wesley, Reading, Mass., 1975.

2. N. Sharon and H. Lis, Chem. Eng. News, 58 (13), 21 (1981).

3. H. Sumitomo and K. Kobayashi, Yuki Gosei Kagaku, 42, 575 (1984).

4. J. M. J. Fréchet and C. Schuerch, J. Am. Chem. Soc., 93, 492 (1971).

5. G. Excoffier, D. Y. Gagnaire, and M. R. Vignon, Carbohydr. Res., 46, 201 (1976).

6. S.-H. L. Chiu and L. Anderson, Carbohydr. Res., 50, 227 (1976).

7. J. H. Pazùr, Adv. Carbohydr. Chem. Biochem., 39, 405 (1981).

8. R. J. Baues and G. R. Gray, J. Biol. Chem., 252, 57 (1977).

9. R. L. Schnaar, P. H. Weigel, M. S. Kuhlenschmidt, Y. C. Lee, and S. Roseman, J. Biol. Chem., 253, 7940 (1978).

10. P. H. Weigel, R. L. Schnaar, M. S. Kuhlenschmidt, E. Schmell, R. T. Lee, Y. C. Lee, and S. Roseman, J. Biol. Chem., 254, 10830 (1979).

11. H. Sumitomo and M. Hasegawa, Polym. Prepr. Jpn., 29, 56 (1980).

12. H. Bader, H. Ringsdorf, and J. Skura, Angew. Chem. Int. Ed. Engl., 20, 91 (1981).

13. N. K. Kochetkov, B. A. Dmitriev, A. Y. Chernyak, and A. B. Levinsky, Carbohydr. Res., 110, C16 (1982).

14. A. Harada, M. Furue, and S. Nozakura, Macromolecules, 9, 701 (1976).

15. A. Harada, M. Furue, and S. Nozakura, Macromolecules, 10, 676 (1977).

16. K. Kobayashi, H. Sumitomo, and Y. Ina, Polym. J., 15, 667 (1983). 
17. K. Kobayashi and H. Sumitomo, Macromolecules, 12, 234 (1980).

18. K. Kobayashi and H. Sumitomo, Polym. J., 13, 517 (1981).

19. I. J. Goldstein and C. E. Hayes, Adv. Carbohydr. Chem. Biochem., 35, 127 (1978).

20. N. Sharon, Sci. Am., 243, 80 (1977).

21. J. W. Becker, G. N. Reeke, Jr., J. L. Wang, B. A. Cunningham, and G. M. Edelman, J. Biol. Chem., 250, 1513 (1975).

22. G. N. Reeke, Jr., J. W. Becker, and G. M. Edelman, J. Biol. Chem., 250, 1525 (1975).

23. S. Kondo, T. Ohtsuka, K. Ogura, and K. Tsuda, $J$. Macromol. Sci. Chem., A13, 767 (1979).

24. S. Moore and K. P. Link, J. Biol. Chem., 133, 293 (1940).

25. L. L. So and I. J. Goldstein, J. Biol. Chem., 242, 1617 (1967).

26. T. J. Williams, N. R. Plessas, and I. J. Goldstein,
Arch. Biochem. Biophys., 195, 145 (1979).

27. H. A. Benesi and J. H. Hildebrand, J. Am. Chem. Soc., 71, 2703 (1949).

28. L. M. Klotz, F. M. Walker, and R. B. Pivan, J. Am. Chem. Soc., 68, 1486 (1946).

29. I. M. Klotz and K. Shikama, Arch. Biochem. Biophys., 123, 551 (1968).

30. F. Cramer, W. Saenger, and H. Ch-Spatz, J. Am. Chem. Soc., 89, 14 (1967).

31. L. Wong and J. Smid, J. Am. Chem. Soc., 99, 5637 (1977).

32. R. Sinta and J. Smid, Macromolecules, 13, 339 (1980).

33. J. L. Neal and D. A. I. Goring, Can. J. Chem., 48, 3745 (1970).

34. M. Janado and T. Nishida, J. Solution Chem., 10, 489 (1981).

35. J. Slama and R. R. Rando, Carbohydr. Res., 88, 213 (1981). 